\title{
LATE CONGENITAL SYPHILIS
}

\section{AN ANALYSIS OF 115 CASES}

\author{
BY \\ SYDNEY M. LAIRD \\ Consultant Venereologist, East Anglian Regional Hospital Board
}

The clinical course and manifestations of an infection are subject to modification over the years. Variation in virulence of the infective agent, changes in the immunity or resistance of the population at risk, earlier diagnosis, and more effective treatment are some of the factors responsible for this phenomenon. Congenital syphilis is an example; one seldom sees acute infantile syphilis in England today, and the recognition of late congenital syphilis in children and adults rests on remembering the possibility and on detecting the subtle signs which now represent the stigmata of prenatal infection. A definite proportion of adult persons found to have positive serological tests for syphilis and diagnosed as cases of "latent" acquired infection are in reality examples of late congenital syphilis. An analysis of the findings in 115 cases of late congenital syphilis, seen personally during the past four years, may be of some interest.

Infectious syphilis is endemic to a varying degree in the cities, seaports, and larger towns of England, but in time of peace early syphilis is almost unknown in the rural areas. During and immediately following the first world war many people in these rural areas became infected and for various reasons failed to receive adequate treatment. The progeny of these parents provide the late prenatal cases of syphilis seen in the rural areas today. This generalization may have its exceptions but it undoubtedly applies to East Anglia.

Age, Sex, and Reasons for Discovery of 115 Cases

The group comprised 38 ( 33 per cent.) males and 77 (66 per cent.) females. The youngest and oldest patients at the time of diagnosis were aged respectively 3 and 75 years. The distribution in age groups is shown in Table $\mathrm{I}$.

It will be seen from Table I that 90 per cent. of cases were diagnosed before the age of 40 years, and 82 per cent. before the age of 30 years.

E
TABLE I

AGE AT TIME OF DIAGNOSIS IN 114* CASES OF CONGENITAL SYPHILIS

\begin{tabular}{|c|c|c|c|}
\hline \multirow{2}{*}{$\begin{array}{l}\text { Age at Diagnosis } \\
\text { (years) }\end{array}$} & \multicolumn{2}{|c|}{ Sex } & \multirow{2}{*}{ Total } \\
\hline & Male & Female & \\
\hline $\begin{array}{cc}1-9 & . \\
10-19 & . \\
20-29 & . \\
30-39 & . \\
40-49 & . \\
50-59 & . \\
\text { Over } 60 & .\end{array}$ & $\begin{array}{r}10 \\
10 \\
10 \\
4 \\
1 \\
1 \\
2\end{array}$ & $\begin{array}{r}12 \\
20 \\
32 \\
5 \\
4 \\
3 \\
0\end{array}$ & $\begin{array}{r}22 \\
30 \\
42 \\
9 \\
5 \\
4 \\
2\end{array}$ \\
\hline Total .. & 38 & 76 & 114 \\
\hline
\end{tabular}

* In one of the 115 cases the age was not traced.

Table II shows the reason for taking the blood test in 111 patients. In 112 cases of congenital syphilis 95 had positive and seventeen negative serological tests (Wassermann reaction and/or Kahn test).

TABLE II

REASON FOR TAKING BLOOD TEST IN 111 PATIENTS

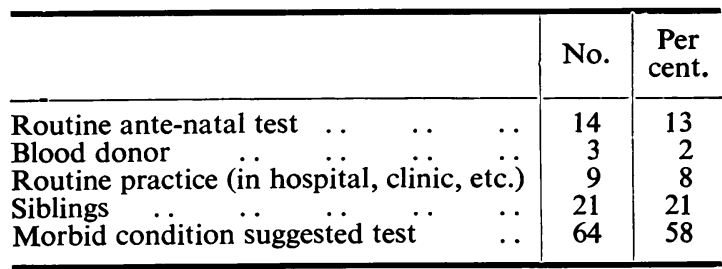

Involvement of the Special Sense Organs.-Interstitial keratitis is almost always due to congenital syphilis. It was present in 45 (39 per cent.) of this series of 115 cases. The sex and age group at time of onset are shown in Table III (overleaf).

In addition, seven other cases presented corneal opacities from previous interstitial keratitis on direct 
clinical examination of the eyes. Of 58 patients in which examination of the optic fundi was recorded, thirteen showed evidence of choroiditis, and nine of these thirteen had neither interstitial keratitis nor corneal scars. Thus, positive findings were present in the eyes alone in at least 61 patients, both sexes being equally affected. Bilateral nerve deafness was found in seven females and one male, a difference the significance of which is difficult to explain.

TABLE III

SEX AND AGE GROUPS OF 45 CASES OF INTERSTITIAL KERATITIS

\begin{tabular}{|c|c|c|c|c|c|c|}
\hline \multirow{3}{*}{$\begin{array}{l}\text { Age Group } \\
\text { (years) }\end{array}$} & \multicolumn{4}{|c|}{ Sex } & \multirow{2}{*}{\multicolumn{2}{|c|}{ Total }} \\
\hline & \multicolumn{2}{|c|}{ Male } & \multicolumn{2}{|c|}{ Female } & & \\
\hline & No. & $\%$ & No. & $\%$ & No. & $\%$ \\
\hline $\begin{array}{c}1-9 \\
10-19 \\
20-29 \\
30-39 \\
40-49\end{array}$ & $\begin{array}{l}6 \\
5 \\
6 \\
1 \\
0\end{array}$ & $\begin{array}{r}13 \\
11 \\
13 \\
2 \\
-\end{array}$ & $\begin{array}{l}6 \\
9 \\
7 \\
2 \\
3\end{array}$ & $\begin{array}{r}13 \\
20 \\
15 \\
4 \\
6\end{array}$ & $\begin{array}{r}12 \\
14 \\
13 \\
3 \\
3\end{array}$ & $\begin{array}{r}27 \\
32 \\
29 \\
6 \\
6\end{array}$ \\
\hline Total & 18 & 40 & 27 & 60 & 45 & 100 \\
\hline
\end{tabular}

Facial Appearance.-The facies described by Stokes is readily appreciated by the experienced syphilologist but its definition in words is extremely difficult. It may include in varying degree frontal bossing, the photophobic habitus, wide-spacing of the orbits, corneal scarring, the impression of fatigue or unalertness in the eyes, "saddle-nose" with flaring of the nostrils, and rhagades. A suggestive facies was present in 52 out of 98 patients in whom the appearance of the face was noted. It was noted more frequently in the female ( 62 per cent.) than in the male ( 35 per cent.). "Saddle-nose" was uncommon, and it again was more frequent in the female ( 7 per cent.) than the male ( 1 per cent.). Some degree of rhagades, usually slight, was noted in seven out of 32 males and in eighteen out of 64 females, a total of 25 out of 96 cases.

Dental Stigmata.-The permanent upper central incisor teeth often provide invaluable evidence for the diagnosis of congenital syphilis ; their absence in a young person whose other teeth are present may arouse suspicion subsequently justified by the discovery of other clinical and serological confirmation of congenital syphilis. They erupt about the fifth year; the development of each incisor takes place from three denticles during the last few weeks of intra-uterine life and the first year of the infant's separate existence. When the foetus is infected with syphilis the growth of the middle denticle is suppressed or modified to some degree and the two lateral denticles by continued and uncompensated growth, produce the bulging sides and antero-posterior thickening seen in the erupted tooth. The absence of growth from the middle denticle results in the notching of the biting edge which is a prominent feature of the classical Hutchinsonian incisor. These changes have been demonstrated radiologically in the unerupted tooth as early as the third year.

The permanent first molar, which erupts about the sixth year, may also suffer developmental damage due to prenatal syphilis. In such circumstances the enamel is unduly prominent bulging up as a shoulder above and around the crown of the tooth. From well inside this margin spring the four defective and dwarfed cusps. Decay is rapid, resulting in cross-ribbing which gives the mulberry appearance described by Moon.

These dental stigmata vary greatly in degree and, though often obvious at first glance, may well be missed except by the experienced observer. In the present series the permanent upper central incisor teeth were affected in 49 of 71 patients, and abnormality of the permanent first molars was noted in twenty of 73 patients. These dental stigmata were shared equally by both sexes.

Bones and Joints.-Syphilitic periostitis is not uncommon in the long bones and in the bones of the skull, and may result in permanent thickening; frontal bossing and "sabre" tibiae are extreme examples. Two bones, the clavicle and the tibia, are particularly accessible to clinical examination and often provide valuable evidence in the diagnosis of congenital syphilis. The inner third of the clavicle, usually the right, and more commonly in males, often presents definite thickening (seventeen out of 32 males, and nineteen out of 63 females). The middle third of the anterior border of the tibia is the typical site and its edge may be irregular as well as prominent. With experience, changes of a slight degree can be detected clinically but only more marked cases give radiological confirmation. These changes are noted more frequently in the male (twenty out of 32) than the female (26 out of 63), probably because the tibia is more readily palpated in the male. Both tibiae may be affected, but thickening is noted more often in the right tibia.

The symmetrical, painless hydrarthrosis of the knees described by Clutton is a relatively rare manifestation of congenital syphilis (three out of 38 males, and only one out of 77 females). When it occurs it is often associated with active interstitial keratitis and, in its initial stages, may be unilateral and painful. 
Other Findings.-Though by no means diagnostic, a high palatal arch occurs in a definite proportion of patients with congenital syphilis (fifteen out of 33 males, and eleven out of 63 females). Ulnar deviation of the middle finger falls into a similar category.

\section{Tertiary Lesions in Congenital Syphilis}

Gummata occurred in 17 per cent. of 94 patients. The palate and the testes are the common sites and consequently more males than females are affected (nine out of 34 males, and seven out of 60 females).

Gummatous involvement of the skin, healed or actively ulcerating, was noted in eight patients, the sites affected being the legs (six cases), the arm (one case), and the sacral area and buttocks (one case). Other gummata involved the palate (two cases), larynx (one case), tibia (one case), clavicle (one case), testis (two cases) and glans penis (one case).

Parenchymatous neurosyphilis was noted clinically in six out of 93 cases, including four patients with juvenile tabes and optic atrophy; normal findings were reported in 32 out of 38 patients in whom the cerebrospinal fluid was examined.

\section{Examination of Parents and Siblings}

It proved possible to take a blood test from the mother in 41 cases ( 38 positive), and from the father in twenty cases (nine positive). In 31 cases the mother had died, and the father was dead in another 31 cases. Fifty-six siblings were examined and 60 per cent. were found to have congenital syphilis, although not all were seropositive. The mothers' obstetric record contained a history of stillbirths and/or infantile deaths in 24 cases, but 36 pregnancies in 24 patients with congenital syphilis resulted in 35 healthy children and only one stillbirth.

\section{Diagnosis of Late Congenital Syphilis}

Diagnosis may be obvious or extremely difficult. It may only be reached after a meticulous history and examination of the patient, study of the mothers' obstetric record ( 20 per cent. have had miscarriages and stillbirths), and enquiry to discover a history of interstitial keratitis or nerve deafness in the siblings. If available, parents and siblings should be examined, and this is often only achieved with much perseverance, patience, and tact after gaining the patient's confidence and cooperation. Valuable negative evidence may be obtained by examination of the patient's marital partner and children. By these means the experienced syphilologist will achieve the accurate diagnosis which is of extreme importance on account of the family implications, the treatment of the patient, and the prognosis, particularly in regard to marriage and child-bearing. A diagnosis of "latent" acquired syphilis should never be made until the possibility of late congenital infection has been considered and thoroughly excluded. 